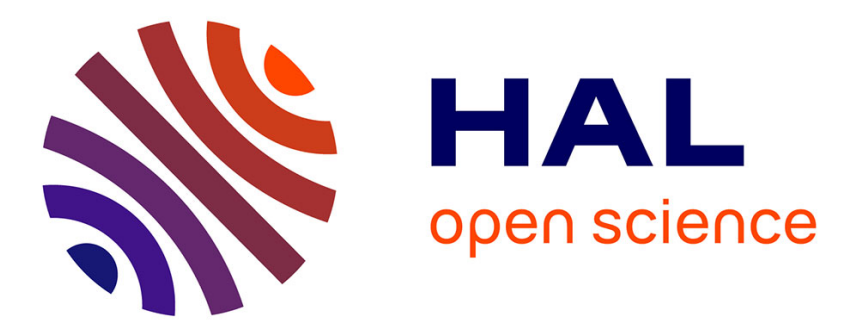

\title{
In situ X-ray tomography densification of firn: The role of mechanics and diffusion processes
}

Alexis Burr, Pierre Lhuissier, Armelle Philip, Christophe L. Martin

\section{To cite this version:}

Alexis Burr, Pierre Lhuissier, Armelle Philip, Christophe L. Martin. In situ X-ray tomography densification of firn: The role of mechanics and diffusion processes. Acta Materialia, 2019, 167, pp.210-220. 10.1016/j.actamat.2019.01.053 . hal-02067389

\section{HAL Id: hal-02067389 \\ https://hal.science/hal-02067389}

Submitted on 21 Oct 2021

HAL is a multi-disciplinary open access archive for the deposit and dissemination of scientific research documents, whether they are published or not. The documents may come from teaching and research institutions in France or abroad, or from public or private research centers.
L'archive ouverte pluridisciplinaire HAL, est destinée au dépôt et à la diffusion de documents scientifiques de niveau recherche, publiés ou non, émanant des établissements d'enseignement et de recherche français ou étrangers, des laboratoires publics ou privés.

\section{(ㄷ)(1) $\$$}

Distributed under a Creative Commons Attribution - NonCommercial| 4.0 International 


\title{
In situ X-ray tomography densification of firn: the role of mechanics and diffusion processes.
}

\author{
Alexis Burr ${ }^{\mathrm{a}, \mathrm{b}, *}$, Pierre Lhuissier ${ }^{\mathrm{a}}$, Christophe L. Martin ${ }^{\mathrm{a}}$, Armelle Philip ${ }^{\mathrm{b}, *}$ \\ ${ }^{a}$ Univ. Grenoble Alpes, CNRS, Grenoble INP ${ }^{1}$, SIMaP, 38000 Grenoble, France \\ ${ }^{b}$ Univ. Grenoble Alpes, Grenoble INP ${ }^{1}$, CNRS, IRD, IGE, 38000 Grenoble, France
}

\section{Abstract}

One of the most efficient proxy methods for paleoclimatology consists of obtaining data previously preserved within polar ice cores. Models for past climate reconstruction are based in particular on the characterization of entrapped gases in ice closed pores. Improving the temporal accuracy of these models requires a better understanding of firn densification mechanisms. In particular, the interplay between viscoplastic deformation and diffusion processes for pore closure is not well understood. In this work, we describe the first in situ laboratory densification experiments on polar firn retrieved from Antarctica with live characterization by X-ray tomography. Our in situ tests allow for the first time to approximately access the process of pore closure in ice, which takes thousands of years to occur in Antarctica, from visualizations and quantitative analyses of short time laboratory experiments. The parameters of pore separation and closure and the microstructural changes that accompany them are monitored. We show that densification of polar

\footnotetext{
*Corresponding authors

Email addresses: alexis.burr@simap.grenoble-inp.fr (Alexis Burr), armelle.philip@univ-grenoble-alpes.fr (Armelle Philip)

${ }^{1}$ Institute of Engineering Univ. Grenoble Alpes
} 
firn and pore closure could be replicated at higher strain rate and warmer temperature. Experiments allow the viscoplastic part of the firn deformation to be decoupled from the diffusion mechanisms that occur at high temperature. Our results show that density alone is not sufficient to predict the close-off density at which gases get entrapped. More generally, the method laid out here may find useful application in the domain of high temperature powder compaction, for which pore closure and grain growth are significant process parameters.

Keywords: firn, X-ray tomography, pore closure, in situ compaction

Introduction

2 Polar firn contains a large part of the history of atmospheric air in its 3 pores [1]. Thanks to the progressive densification of snow to ice, gases are 4 entrapped in firn, and progressively buried down in the ice core. This pro5 cess occurs by gradual pore closure with the age of gases being distributed 6 for a given depth. Thus, dating a particular atmospheric composition, and 7 relating it to changes in past climate temperature is challenging. In particunderstanding of firn densification and gas-trapping mechanisms. 
leads to progressive closure and separation of pores to form individual closed pores. At the close-off depth (COD), these pores are fully isolated from the surface, i.e. air can no longer be pumped out from the firn.

These changes in gas transport mechanisms originate from different densification mechanisms. First, snow undergoes grain rearrangement and sintering until a density $\rho=550 \mathrm{~kg} \cdot \mathrm{m}^{-3}$ is reached. Further densification takes place by viscoplastic deformation of grains. The order of magnitude of the densification rate being typically between $10^{-12}$ and $10^{-9} \mathrm{~s}^{-1}$ depending of the polar sites, Maeno and Ebinuma [3] proposed that deformation proceeds by a combination of dislocation creep, which is the dominant mechanism, and diffusion creep (boundary or lattice diffusion depending on the temperature). The last stage of densification is porosity-related. When the density exceeds about $840 \mathrm{~kg} \cdot \mathrm{m}^{-3}$, pores are closed and further shrinking is driven by the difference between their internal pressure and the larger external stress.

As pore closure is a very slow process, there is no direct observation of this phenomenon in the field as it would take many decades to capture it. However, ex situ characterizations of post mortem firn samples have been performed, in particular with the use of X-ray tomography $[4,5,6,7]$. This enabled the amount of closed pores to be quantified and to relate it to gas transport in the firn. The significant geometrical evolution of pores with depth can also be characterized. Still, the closure process and its accompanying microstructural evolution can only be assumed in ex situ observations, while in situ observations in real time would give much more valuable information on the phenomena at play. Therefore, in situ observations under laboratory conditions provide very promising tests to study densification 
mechanisms and pore closure within a reasonable time frame. To our best knowledge, no in situ compaction of firn under X-ray microtomography has been attempted yet. In other words, pore closure has not been followed in situ during mechanical tests.

Mechanical tests on firn are relatively scarce. Some laboratory experiments on dense snow and natural firn have been reported in the literature. For instance, Landauer [8] performed uniaxial tests up to $630 \mathrm{~kg} . \mathrm{m}^{-3}$ density and recorded stresses of the order of $0.3 \mathrm{MPa}$ for strain rates of $4 \cdot 10^{-4} \mathrm{~s}^{-1}$. Ebinuma and Maeno [9] carried out creep tests on denser laboratory snow for various initial densities (above $550 \mathrm{~kg} \cdot \mathrm{m}^{-3}$, similar to natural firn), and went further than $850 \mathrm{~kg} \cdot \mathrm{m}^{-3}$. They concluded that above a critical density, which depends on the applied stress, dislocation creep governs deformation [10]. Meussen et al. [11] offer a more recent and complete work on creep experiments on natural firn with a large range of tested densities. Results for densities of approximately $850 \mathrm{~kg} \cdot \mathrm{m}^{-3}$ exhibited less than $1 \%$ of strain for an eighty-hour experiment under $0.5 \mathrm{MPa}$ and at $-20^{\circ} \mathrm{C}$. For those large densities (close to the close-off density), firn exhibited a similar behavior to polycrystalline ice. In short, in these tests, applied stresses are about the same order of magnitude than in the firn core (ranging from 0.1 to $0.7 \mathrm{MPa}$ ) but those experiments were too lengthy to allow for X-ray tomography. These results exemplify the range of mechanical responses of our material from the extremely porous to the extremely dense firn and provide the necessary conditions for displacement-controlled tests. Indeed, decreasing by a factor 10 the time of the experiment will lead to significantly larger stresses. Dislocation creep is also expected to be the dominant microstructural mechanism 
under such conditions.

Rolland Du Roscoat et al. [12] were the first to perform in situ X-ray diffraction contrast tomography on snow samples under slow creep, allowing grains to be differentiated from one another (with stresses lower than $0.14 \mathrm{MPa}$ and initial densities lower than $\left.500 \mathrm{~kg} \cdot \mathrm{m}^{-3}\right)$. These authors followed the intragranular deformation of snow grains as small intragranular disorientations were observed. These results emphasized that the anisotropic viscoplasticity of ice crystals should be considered even for snow. Other compaction tests on snow also revealed that deformation is mainly controlled by pressure sintering, but is also dependent on the density and on grain specific surface area $[13,14,15]$. Still, in situ studies of snow mostly consist of following time lapse metamorphism for different types of snow [16] and with controlled thermal gradients or other particular conditions [17, 18]. The ultimate goal is usually to compute snow effective properties [19] or model snow behavior $[20,21,22]$. Moreover, curvature change is a key feature of snow metamorphism and its investigation reveals underlying processes at work $[23,24]$. In particular, rounding and smoothing of snow grains along with grain growth and specific surface area decrease, demonstrate time and temperature influence $[25,26]$.

For firn typical densities (ranging from $550 \mathrm{~kg} \cdot \mathrm{m}^{-3}$ to $912 \mathrm{~kg} . \mathrm{m}^{-3}$ ), the evolution of pore curvature, and time and temperature effects should be noticeable in laboratory conditions (day-long experiment at $-10^{\circ} \mathrm{C}$ ). In this work, we investigate the effects of time, temperature and densification-rates on pore closure, microstructure evolution, and pore curvatures for large initial densities $\left(\rho>780 \mathrm{~kg} \cdot \mathrm{m}^{-3}\right)$. In particular, we make an attempt to discern the 
effects of dislocation creep and diffusion creep by using two relevant firn parameters: the closed porosity ratio and the connectivity index. To that end, in situ compaction tests are performed on natural firn characterized by X-ray tomography.

\section{Methods}

\section{Strategy}

This work aims at monitoring, in a time frame of a few hours, the densification of polar firn by X-ray micro-tomography. This means experimental strain rates $\left(\approx 10^{-6}-10^{-5} \mathrm{~s}^{-1}\right)$ six or seven orders of magnitude larger than during natural densification in polar ice cap, as well as warmer temperature $\left(-10^{\circ} \mathrm{C}\right.$ in laboratory instead of $-55^{\circ} \mathrm{C}$ in the East Antarctica plateau for instance). Power law creep is the dominant mechanism for such strain rates at high temperature. Diffusion mechanisms and processes such as sintering or grain growth are not expected to occur in an eight-hour experiment. To assess the impact of the different mechanisms on firn, experimental tests and in situ inspection were carried out. Ex situ characterization was first performed and published in Burr et al. [7], thus providing a reference state for the firn from Dome C (East Antarctica plateau) ${ }^{2}$. The ex situ data set is composed of 29 samples extracted from the same ice core at different depths, above and below the close-off depth. Ex situ samples were not subjected to any treatment. In contrast, we refer to in situ samples when samples extracted from the ice core are thereafter mechanically tested or thermally treated. In situ

\footnotetext{
${ }^{2}$ Volsol ice core, grant ANR NT09-431976-VOLSOL)
} 


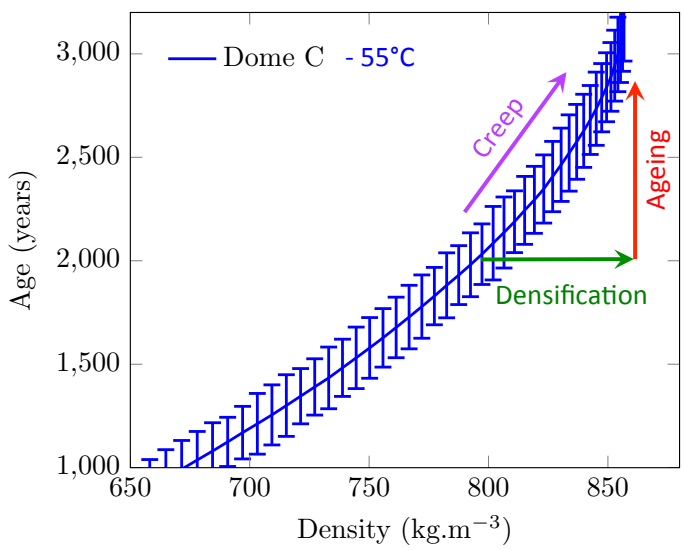

Figure 1: The experimental strategy developed in this work. Ice age against density for Dome C [27] together with the proposed paths in the experimental procedure: mechanical densification under oedometric compaction at $-10^{\circ} \mathrm{C}$ followed by ageing (heat treatment) at $-2{ }^{\circ} \mathrm{C}$. Creep tests on firn are also performed at $-2{ }^{\circ} \mathrm{C}$.

compacted samples are artificially densified at $-10^{\circ} \mathrm{C}$ by means of an oedometric compaction device, while being characterized by X-ray tomography. Additionally, a few samples are kept at high temperature at $-2{ }^{\circ} \mathrm{C}$ for five months and analyzed afterward. A third set of in situ samples are submitted to creep also at $-2{ }^{\circ} \mathrm{C}$ for five months. This procedure is illustrated by the evolution of the ice core age with density in Fig. 1. The compaction test densifies the material, while the heat treatment at $-2{ }^{\circ} \mathrm{C}$ ages it. The creep tests attempt to couple stress and temperature for densification. The accompanying microstructures of these samples are compared with ex situ samples from the same density, corresponding to different firn depths: $79.87 \mathrm{~m}, 89.5 \mathrm{~m}$ and $94.5 \mathrm{~m}$. 


\section{Compaction device}

A special cold cell was developed and adapted to a compaction device to perform mechanical tests on the firn. A motor controls the vertical motion of a piston via gears. A load cell is mounted under the piston and a software enables the displacement of the piston to be controlled in a rather large range of velocities (between 0.1 and $10 \mu \mathrm{m} . \mathrm{s}^{-1}$ ). The cold cell is fixed on the compaction device. It consists of a cold air input and a cover that bears the load (Fig. 2). The sample is set between the piston and the cover. The cover was designed to follow several specifications. It should sustain a sufficient load, be thermally insulated and should moderately absorb X-rays.

Figure 2 shows the apparatus inside the laboratory tomograph. Cold air flows through the cell at $-10^{\circ} \mathrm{C}$ thanks to the combination of an air dryer and a cryostat. The diameter of firn samples are adjusted to the PMMA socket with a lathe, in order to impose oedometric conditions before subsequent treatment. These conditions are required to avoid issues that could occur for such a granular material in uniaxial compression (grains may detach easily during the compaction and lead to catastrophic failure). An oedometric test is a compaction test, which reproduces satisfactorily the strain state imposed in ice caps and soils, and which models in this work an artificial densification of firn.

\section{Tested samples}

Ex situ and in situ samples are $12 \mathrm{~mm}$ in diameter and their height is in the $20-30 \mathrm{~mm}$ range. All samples are characterized at $-10^{\circ} \mathrm{C}$ in an Easytom XL nano tomograph from RX Solutions, at an acceleration voltage of $60 \mathrm{kV}$ and a target current of $166 \mu \mathrm{A}$. Scans have a helical geometry enabling the 


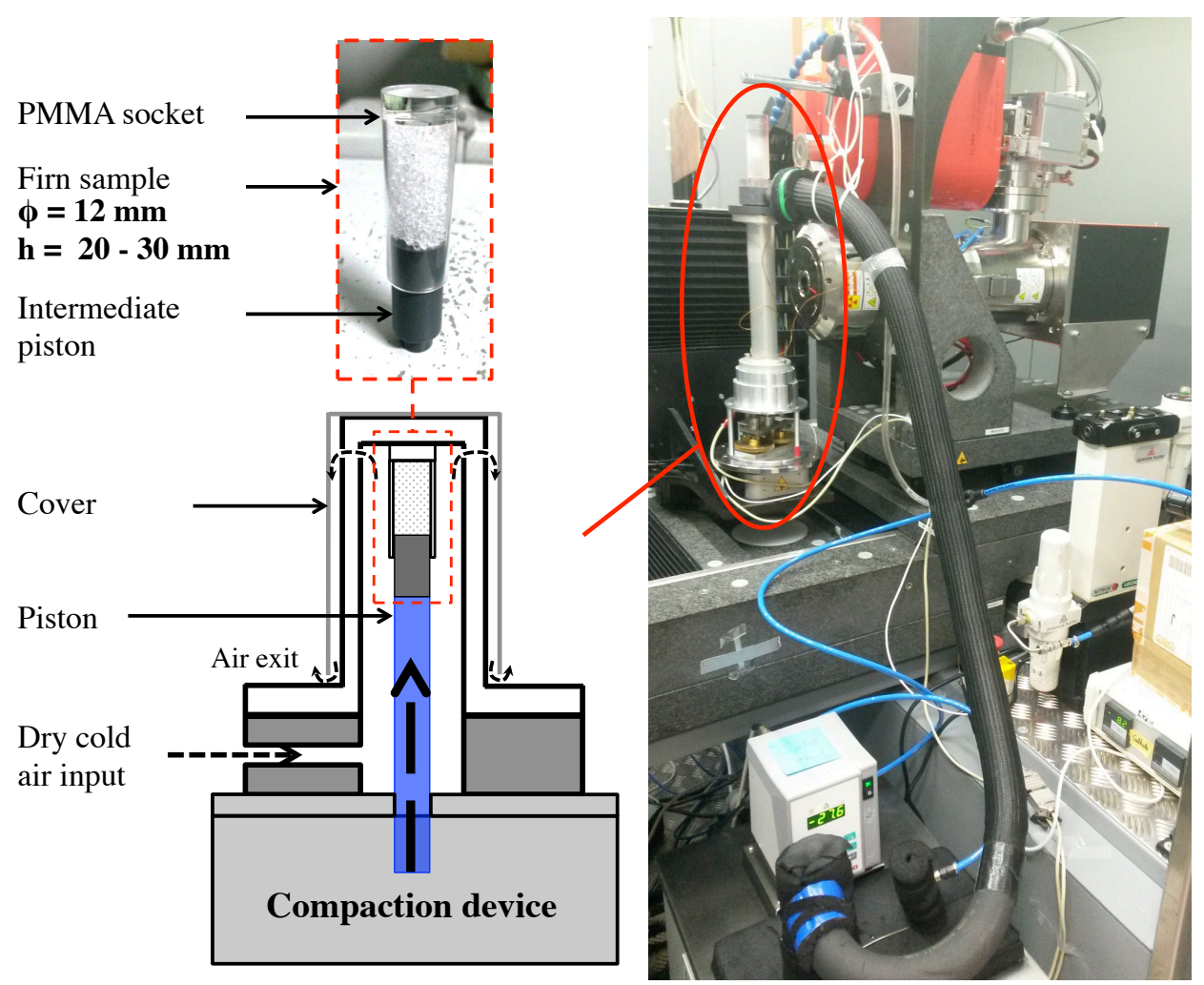

Figure 2: The apparatus inside the laboratory tomograph with the compaction device highlighted in a red ellipse. The firn sample is shown inside its PMMA socket (oedometric conditions). Cold air flows in the cell at $-10{ }^{\circ} \mathrm{C}$.

sample to be imaged on its full length. Multiple scans on the same ex situ sample have barely shown any effect of the X-rays and of the air flow on the pore shape nor density [28]. Voxel size is $12 \mu \mathrm{m}$ for ex situ conditions and $15 \mu \mathrm{m}$ for in situ conditions. After 3D image reconstructions with the filteredback projection algorithm, all image analyses and parameter determination were carried out using the free software Fiji [29] combined with the plugin Analysis 3D [30]. To comply with the method proposed in Burr et al. [7], a cylindrical region of interest of $9.6 \mathrm{~mm}$ in diameter is extracted from volume 
image after thresholding of the ice phase.

In situ compacted samples were tested at different displacement rates. Tests were interrupted to scan samples at different densities and ensure a stable microstructure. After 10 minutes of viscoplastic relaxation, a 25minute scan was performed, to avoid blurred 3D images. Interruptions of tests roughly lead to a $30 \%$ stress drop (see SI for a stress-time curve). Four samples were successfully scanned during in situ compaction. They originate from the same slice of the Dome $\mathrm{C}$ ice core at $79.92 \mathrm{~m}$ depth and are detailed in Table 1. The nomenclature of samples relates to their depth in the ice core. When samples $80_{3}$-comp, $80_{4}$-comp, $80_{5}$-comp and $80_{6}$-comp were in oedometric conditions, the displacement rate of the piston was kept constant leading to strain rates in the range $\left[2 \cdot 10^{-6} \mathrm{~s}^{-1}, 1.5 \cdot 10^{-5} \mathrm{~S}^{-1}\right]$. Displacement rates were set so that there were twice the one of $80_{3}$-comp for $80_{4}$-comp and $80_{6}$-comp, and three times larger for $80_{5}$-comp. Note that strain rates above $\approx 4 \cdot 10^{-5} \mathrm{~s}^{-1}$ lead to micro-cracks within the firn. Care was taken to ensure a correct positionning of samples before the desired speed could be applied. This delicate pre-positioning of samples could last up to 5 hours, leading to a total compaction time of 8 to 10 hours. Digital volume correlation on grey level images indicated that radial strain reached between $1 \%$ and $2.5 \%$ in the first few hours of the test, corresponding approximately to an axial strain $\varepsilon \approx 4 \%[28]$.

After compaction, samples are denoted with the suffix -comp. The particular sample $80_{6}$ is submitted to two consecutive treatments: first a compaction $\left(80_{6}\right.$-comp) and then a heat treatment $\left(80_{6}\right.$-comp-temp). Table 1 lists the initial designations and densities of all tested samples as well as 

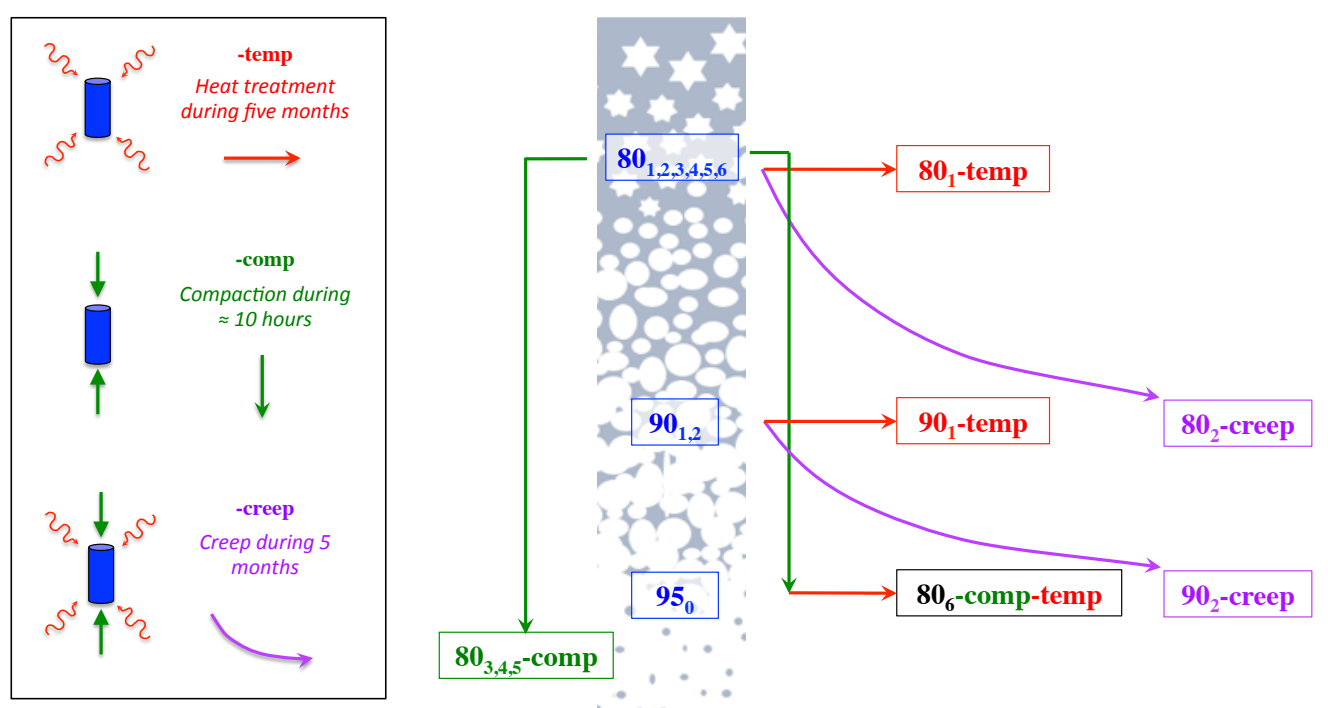

Figure 3: Experimental strategy throughout this work. The red path denotes heat treatment with no applied stress. The green path denotes densification under mechanical compaction. The purple path denotes densification under creep for 5 months. Samples are denominated by their initial depth in the ice core. For example, sample $80_{6}$ was drilled at $80 \mathrm{~m}$ depth, compacted $\left(80_{6}\right.$-comp $)$ and finally submitted to heat treatment (80 ${ }_{6}$-comp-temp).

their designations and densities after a 5 months heat treatment at $-2{ }^{\circ} \mathrm{C}$ (denoted with a suffix -temp). These temperatures and duration were chosen to keep a reasonable time frame. Note that samples $80_{2}$ and $90_{2}$ crept during heat treatment as a load was applied on them (denoted with a suffix -creep, axial stress $\approx 0.3$, and $\approx 0.7 \mathrm{MPa}$, respectively), in contrast to samples $80_{1}$ and $90_{1}$ which only aged at elevated temperature without external stress. The heat treatment was performed in two hermetic boxes with large humidity content to avoid sublimation (RH74\% and RH99.9\%, respectively). Samples inside their PMMA socket were also wrapped in plastic foils to limit 
sublimation. Figure 3 illustrates the various treatments applied on samples 80 and 90 .

Microstructure

After experiments, all in situ tomographic samples are cut in half (-comp, -temp and -creep), and the thin section of each half is analyzed (typically $\approx 25 \mu \mathrm{m})$. Microstructures and grain orientations are revealed thanks to polarized light using an Automatic Ice Texture Analyzer (AITA) [31]. Mean grain size is then determined for each thin section by averaging the surface area of all grains (using Fiji [29]). For ex situ samples, slices of ice core retrieved at the same depth than in situ samples are analyzed with thin sections of $20 \times 20 \mathrm{~mm}^{2}$. Therefore the mean grain size of ex situ samples is more statistically representative than for in situ tomographic samples (algorithm for image analyses and evolution with depth of the ex situ microstructure and $\mathbf{c}$ axis orientations are given in Burr [28]). 


\begin{tabular}{|c|c|c|c|c|c|c|c|c|}
\hline \multicolumn{3}{|c|}{ Ex situ samples } & \multicolumn{6}{|c|}{ In situ samples } \\
\hline $\begin{array}{l}\text { Initial } \\
\text { name }\end{array}$ & $\begin{array}{l}\text { Depth } \\
(\mathrm{m})\end{array}$ & $\begin{array}{c}\rho_{k} \\
\left(\mathrm{~kg} \cdot \mathrm{m}^{-3}\right)\end{array}$ & State 1 & $\begin{array}{l}\text { Final strain } \\
\text { rate }\left(\mathrm{s}^{-1}\right)\end{array}$ & $\begin{array}{c}\text { Final stress or } \\
\text { dead load (MPa) }\end{array}$ & $\begin{array}{c}\rho_{1} \\
\left(\mathrm{~kg} \cdot \mathrm{m}^{-3}\right)\end{array}$ & State 2 & $\begin{array}{c}\rho_{2} \\
\left(\mathrm{~kg} \cdot \mathrm{m}^{-3}\right)\end{array}$ \\
\hline $95_{0}$ & 94.5 & 829.7 & & & & & & \\
\hline $80_{1}$ & 79.87 & 786.3 & $80_{1}$-temp & & 0 & 784.8 & & \\
\hline $80_{2}$ & 79.92 & 794.1 & $80_{2}$-creep & & $\approx 0.3$ & 810.3 & & \\
\hline $80_{3}$ & 79.92 & 797.8 & $80_{3}$-comp & $3.4 \cdot 10^{-6}$ & $\approx 3$ & 825.1 & & \\
\hline $80_{4}$ & 79.92 & 785.0 & $80_{4}$-comp & $7.6 \cdot 10^{-6}$ & $\approx 4.8$ & 867.8 & & \\
\hline $80_{5}$ & 79.92 & 784.8 & $80_{5}$-comp & $9.3 \cdot 10^{-6}$ & $\approx 5$ & 852.2 & & \\
\hline $80_{6}$ & 79.92 & - & $80_{6}$-comp & $\approx 4 \cdot 10^{-6}$ & $\approx 5.7$ & 828.3 & $80_{6}$-comp-temp & 825.6 \\
\hline $90_{1}$ & 89.5 & 822.3 & $90_{1}$-temp & & 0 & 823.6 & & \\
\hline $90_{2}$ & 89.5 & 821.0 & $90_{2}$-creep & & $\approx 0.7$ & 829.5 & & \\
\hline
\end{tabular}

Table 1: Nomenclature of samples. Ex situ samples are reference states, used as initial states of in situ samples (before any treatment). In situ samples are samples submitted to a treatment. Denotations -comp, -temp and -creep refer respectively to in situ compacted samples at $-10{ }^{\circ} \mathrm{C}$, in situ heat treated samples at $-2{ }^{\circ} \mathrm{C}$ and samples that crept at $-2{ }^{\circ} \mathrm{C}$. Sample $80_{6}$ is first compacted at $-10^{\circ} \mathrm{C}$ and then heat treated at $-2{ }^{\circ} \mathrm{C}$, hence is denoted -comp-temp. Samples $80_{3,4,5}$ are scanned regularly throughout compaction and state 1 refers to their final strain step. Though strain rates and stresses evolve during compaction tests, only the final ones are shown (see supplementary file for curves). Samples come from a slice of Dome C ice core from depths in the range 80 to 95 meters. 


\section{Curvature}

Curvature is supposed to be the driving force of snow metamorphism (surface energy minimization). On 3D images, it is usually described with the mean and Gaussian curvatures $[32,23]$. Here we take advantage of two other measures of local shape introduced by Koenderink and Doorn [33]. The shape index is a measure of the local shape that also differentiates convexities from concavities. It ranges from -1 to +1 . The curvedness is a positive value that quantifies the amount of curvature of the shape. It differentiates well flat surfaces from acute shapes for instance. These measures of shape were successfully used in the metallurgy community, to quantify dendritic growth [34] or to compare dendrites depending on the solidification method used $[35]$.

In the following, curvatures are investigated in the porosity reference framework, such that the surface of an entrapped spherical bubble is considered convex. This is important as we adopt the convention $\kappa_{1}>\kappa_{2}$ for principal curvatures. The shape index $S$ writes :

$$
S=\frac{2}{\pi} \arctan \left(\frac{\kappa_{1}+\kappa_{2}}{\kappa_{1}-\kappa_{2}}\right)
$$

Regarding the curvedness $C$, it is equal to 0 for a perfectly planar surface (infinite curvature radius), and increases as the curvature radius decreases. Its formulation is:

$$
C=\sqrt{\frac{\kappa_{1}^{2}+\kappa_{2}^{2}}{2}}
$$

Local principal curvatures are computed with the software Avizo [36]. The generation of the surface mesh implies the choice of a mesh size. It is achieved by selecting a smoothing parameter in Avizo (set to 3). For the 
actual calculation of curvatures, the user also has to determine how many neighbors are taken into account for the local curvature. Using the ten closest neighbors for local curvatures leads to about 10 to 20 minutes of computation time (Burr [28] for more details). The computation of the curvedness and the shape index gives a 2D histogram which can be interpreted with a scaled probability density $\mathrm{P}(S, C)$. In the following, we chose a normalization such that $\mathrm{P}\left(S_{\max }, C_{\max }\right)=1$ which means that the local surface characterized by the corresponding values $S_{\max }$ and $C_{\max }$ is the most abundant in the sample.

\section{Initial state - ex situ samples}

Figure 4 shows microstructural information for samples from 80 and $90 \mathrm{~m}$ depths at their initial state. Figure 4 is used as a reference state for comparison with in situ samples. The classification of shapes depending on the value of $S$ in the range $[-1 ; 1]$ is also exemplified as layouts in Fig. 4. For instance, a perfectly spherical pore (cap-like shape) would have a shape index equal to 1 , and a perfectly cylindrical pore (ridge-like shape) would have a shape index equal to 0.5 . Figure $4 \mathrm{~b} 1$ shows more closed pores (illustrated in red) than Fig. 4a1 as the sample was taken 10 meters deeper. In both cases, pores are usually rounded with smooth surfaces (Fig. 4a1-b1), as depicted by $\mathrm{S}-\mathrm{C}$ maps in Fig. 4a2-b2. Indeed, their shape span through the saddle-ridge and the dome-like shape (between a ridge and a cap). Looking at the most abundant local surface in the sample, for which $\mathrm{P}\left(S_{\max }, C_{\max }\right)=1$, one can also distinguish the small shift of $S_{\max }$ towards increasing $S$ between samples coming from 80 meters $\left(S_{\max }<0.5\right)$ and 90 meters depth $\left(S_{\max }>0.5\right)$. Variation of the curvedness is relatively low, with the same horizontal shift of the maximum curvedness than for $S_{\max }$. Grains are quite equiaxed and depth 
clearly impacts grain size: $90 \mathrm{~m}$ deep samples exhibit larger grains than $80 \mathrm{~m}$ deep samples (left hand side of Fig. 4a3-b3). In fact, firn grain size increases monotonously with depth in Dome C firn [28, 7]. Finally, orientations of $\mathbf{c}$ axes towards the ice core direction (loading direction) are already discernible for all samples from $80 \mathrm{~m}$ and $90 \mathrm{~m}$ (see right hand side of Fig. 4a3-b3).

\section{Results}

\section{Closed porosity ratio and connectivity index}

Pore closure evolution has been classically investigated by using the closed porosity ratio $[38,39,40,41]$. Recently, we have introduced a parameter defined as the connectivity index, which was found more reliable than the closed porosity ratio to predict the close-off depth and density [7]. The connectivity index is defined by the ratio of the volume of the largest pore to the total pore volume of a sample, and its quantification is less dependent on the analyzed volume, heterogeneities and voxel size than the closed porosity ratio. The closed porosity ratio is defined by the ratio of the closed pore volume to the total pore volume. They both work reversely and vary between 0 and $100 \%$, but the closed porosity ratio is fully dependent of the status of pores (close or open), which is sensitive for the small volumes typically obtained with X-ray tomography in this work. Its quantification is carried out at the scale of the sample and depends on the cut-pore ratio. It does not give values that can be used to characterize a firn layer. That being said, both parameters are calculated and discussed here.

Figure 5a shows the evolution of the closed porosity ratio with density and Figure 5b shows the connectivity index for both types of samples. Ex 

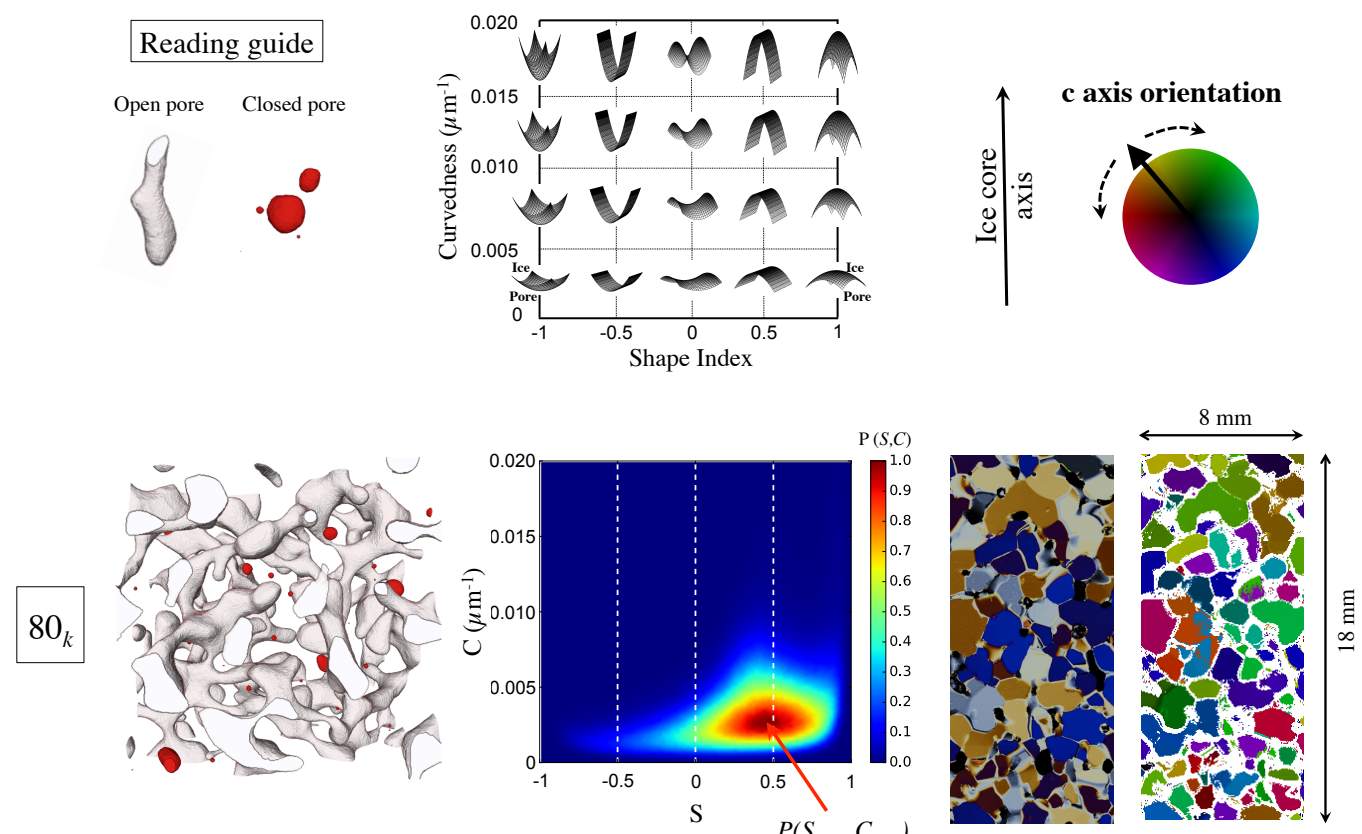

(a1)

(a2)

(a3)

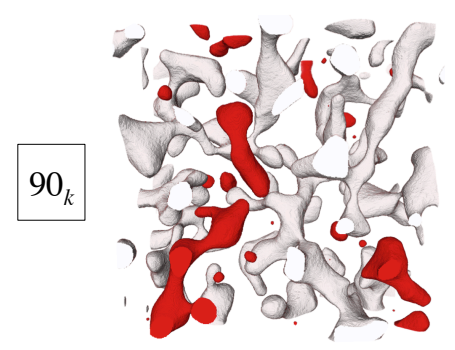

(b1)

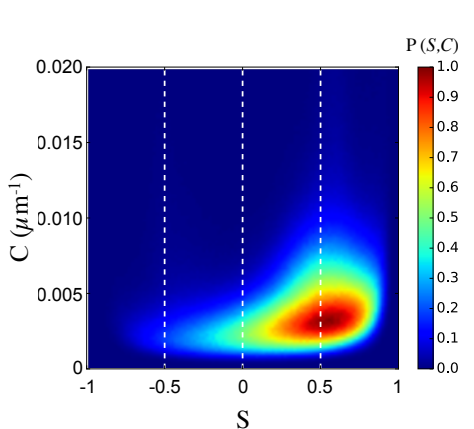

(b2)

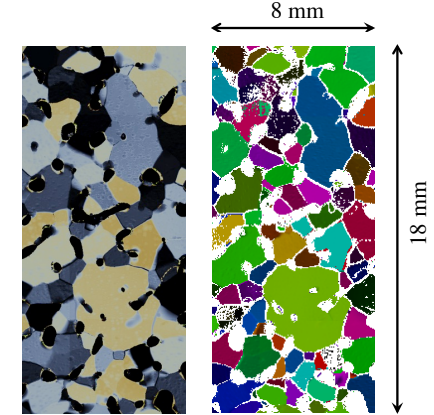

(b3)

Figure 4: Typical initial microstructures and references for samples (a) $80_{k}$ and (b) $90_{k}$ (with $k$ ranging from 1 to 6 for samples $80_{k}$ and being 1 or 2 for samples $90_{k}$ ). Layouts are shown as reading guides. Visualization of open pores (white) and closed pores (red)

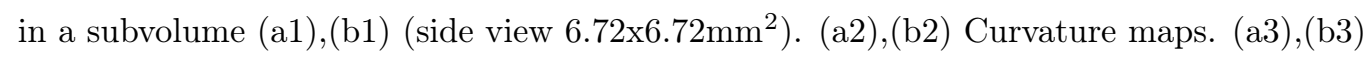
Left hand side : thin sections observed by polarized light illustrating grain size. Right hand side : $\mathbf{c}$ axis reconstruction of the same thin section using the AITA python toolbox [37] (pores and reconstructed pixels with low quality are in white). 


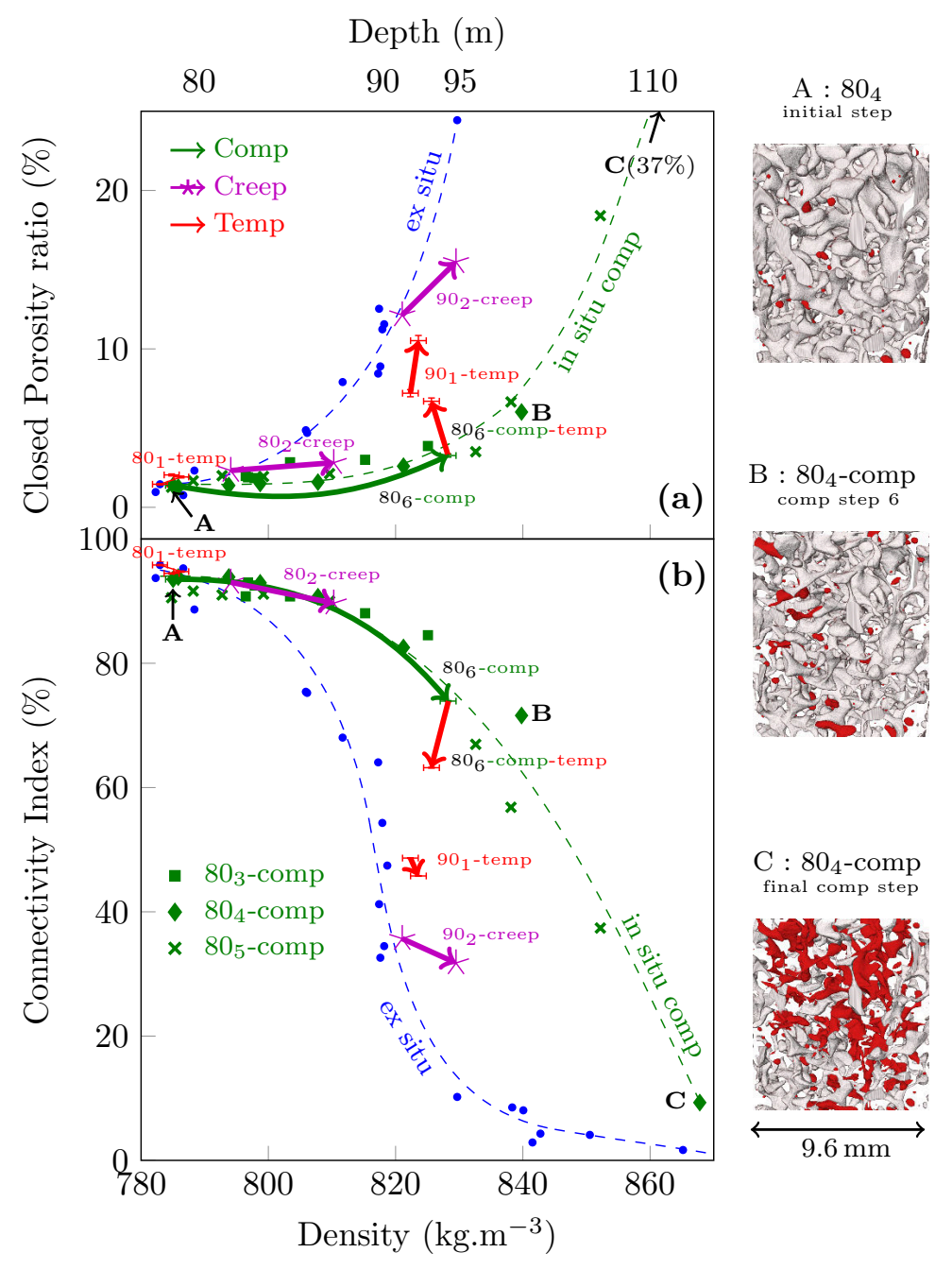

Figure 5: Evolution of the closed porosity ratio (a) and of the connectivity index (b) with density for ex situ and in situ samples. Blue dots depict ex situ samples [7], and green crosses, diamonds and squares depict all strain steps of in situ compacted samples $80_{3,4,5^{-}}$ comp. Blue and green dashed lines serves only to guide the eyes. All other in situ samples are displayed by arrows that link their initial states to their final states. Different steps of compaction of sample $80_{4}$-comp are also visualized with open pores in white and closed pores in red (with $\rho_{A}=785.0 \mathrm{~kg} \cdot \mathrm{m}^{-3}, \rho_{B}=839.8 \mathrm{~kg} \cdot \mathrm{m}^{-3}$ and $\rho_{C}=867.8 \mathrm{~kg} . \mathrm{m}^{-3}$ ). See Fig. 3 and Table 1 for sample color and nomenclature, and supplementary for full in situ visualization of sample $80_{4}$-comp. 
situ points from Burr et al. [7] and their trend have been added in blue, while in situ compacted samples are displayed in green. The red and purple colors correspond respectively to in situ -temp and -creep samples along with their initial states. All points linked by an arrow are the same extracted subvolumes at different states. However, to avoid superimposing arrows, samples $80_{3,4,5}$-comp and their intermediary steps are displayed by green crosses, diamonds and squares, respectively. When required for analyses, error bars have been added. These were calculated by investigating the effects of image processing, voxel size, sample size and pixel connectivities on the studied parameters [7]. Relative errors are $0.15 \%$ for $\rho, 3.1 \%$ for the closed porosity ratio and $0.11 \%$ for the connectivity index. In situ points have been obtained with very different strain rates, but interestingly they all fall on a master curve (displayed by a green dashed line) for the closed porosity ratio and the connectivity index. For any given density, the fraction of closed porosity is larger for ex situ samples. For instance, at $830 \mathrm{~kg} \cdot \mathrm{m}^{-3}$, approximately $24.4 \%$ of pores are closed for ex situ samples, whereas for in situ compacted samples there are only $4.5 \%$ of closed pores. Accordingly, the connectivity index is the largest for in situ compacted samples. In other words, pores are closing at larger densities for in situ compacted samples than for ex situ samples. Tomographic images Fig. 5 illustrate this pore closure process. Note that the minimum value obtained for the connectivity index is $9.3 \%$ with a density value of $867.8 \mathrm{~kg} . \mathrm{m}^{-3}$ (sample $80_{4}$-comp was the most compacted one at the end of the experiment). We have shown that the close-off depth and its corresponding density could be predicted from the abrupt drop and the final plateau of the connectivity index curve (see Burr et al. [7] for details 
on the determination procedure). Here, the final plateau is not reached at $840 \mathrm{~kg} \cdot \mathrm{m}^{-3}$ for in situ samples, meaning that percolation is still possible after compaction up to at least $870 \mathrm{~kg} \cdot \mathrm{m}^{-3}$. This means that using density as the only indicator of the close-off is not correct. Microstructure and densification history also play an important role in determining close-off. It is likely this microstructure effect is partly taken into account when using the temperature of a polar site as a determination parameter for the air volume entrapped in closed pores (e.g. Martinerie et al. [42]).

Figure 5 also displays the closure of pores after heat treatment (red arrows). In fact, a green arrow representing compaction, links $80_{6}$ to $80_{6}$-comp, illustrating a density increase without closing much pores. But, from $80_{6^{-}}$ comp to $80_{6}$-comp-temp, the closed porosity ratio increases from 3.3 to $6.7 \%$ while the density only slightly decreases. In contrast to the closed porosity ratio, the connectivity index drops from 74 to $63 \%$. Depending on the conditions they were submitted to, samples exhibit different trends. Indeed, the density stayed constant within error bars between $80_{1}$ and $80_{1}$-temp, or between $90_{1}$ and $90_{1}$-temp, but an increase of the closed porosity ratio is only noticed between $90_{1}$ and $90_{1}$-temp. Creep tests on samples $80_{2}$ and $90_{2}$ both exhibit an increase in density. However, only the creep test on the deepest sample do close some pores $\left(90_{2}\right.$-creep), while they do not for sample $80_{2^{-}}$ creep. Consistently, the connectivity index decreases for sample $90_{2}$-creep and stagnates for sample $80_{2}$-creep. Pore size being rather large for sample $80_{1}$, the 5 months heat treatment was not sufficient to have pore channels disconnecting from one another, compared to sample $90_{1}$. In brief, compaction tests lead to an increase in density without disconnecting much pores, while 
increasing temperature tends to separate pores for a given density.

Visual inspection of 3D views (see Fig. 4-5-6) gives valuable qualitative information on the porous structure. However, in the following section, a more precise evaluation of the morphological differences is realized by quantifying these changes in terms of curvatures of pores.

Curvature

Figure 6 shows a close-up view within the porosity networks for different samples of approximately the same density $\left(\rho=828 \pm 2 \mathrm{~kg} \cdot \mathrm{m}^{-3}\right)$, but resulting from different process histories. The separation of globular portion of pores is highlighted in blue for samples $80_{6}$-comp and $80_{6}$-comp-temp. Blue ellipses point to sharp dead ends in Fig. 6b1 that appear smaller and rounder in Fig. 6c1. Green ellipses highlight thin channels (Fig. 6b1) that have disappeared after heat treatment (Fig. 6c1). The accentuated curvature after compaction test is illustrated by zoom-ins on the pore network. Samples $95_{0}$ (Fig. 6a2) and 902-creep (Fig. 6d2) do not exhibit marked curved pores, whereas sample $80_{6}$-comp (Fig. 6b2) exhibits sharp pore shapes, characterized by a larger curvedness on pore edges. After heat treatment, sample $80_{6}$-comp-temp exhibit smoother edges as emphasized by red ellipses in Fig. 6c2. The curvedness clearly shows that the sharp shapes and pointy dead-ends are starting to round. Concavities also seem to be reduced and some pore channels are disappearing, thus indicating pore closure during heat treatment.

This morphological evolution of pores is confirmed quantitatively by curvature maps in Figs. $6 a 3$ to d3. As observed on 3D images, the ex situ sample $95_{0}$ depth is very similar to $90_{2}$-creep, which was crept at $-2{ }^{\circ} \mathrm{C}$ during five 

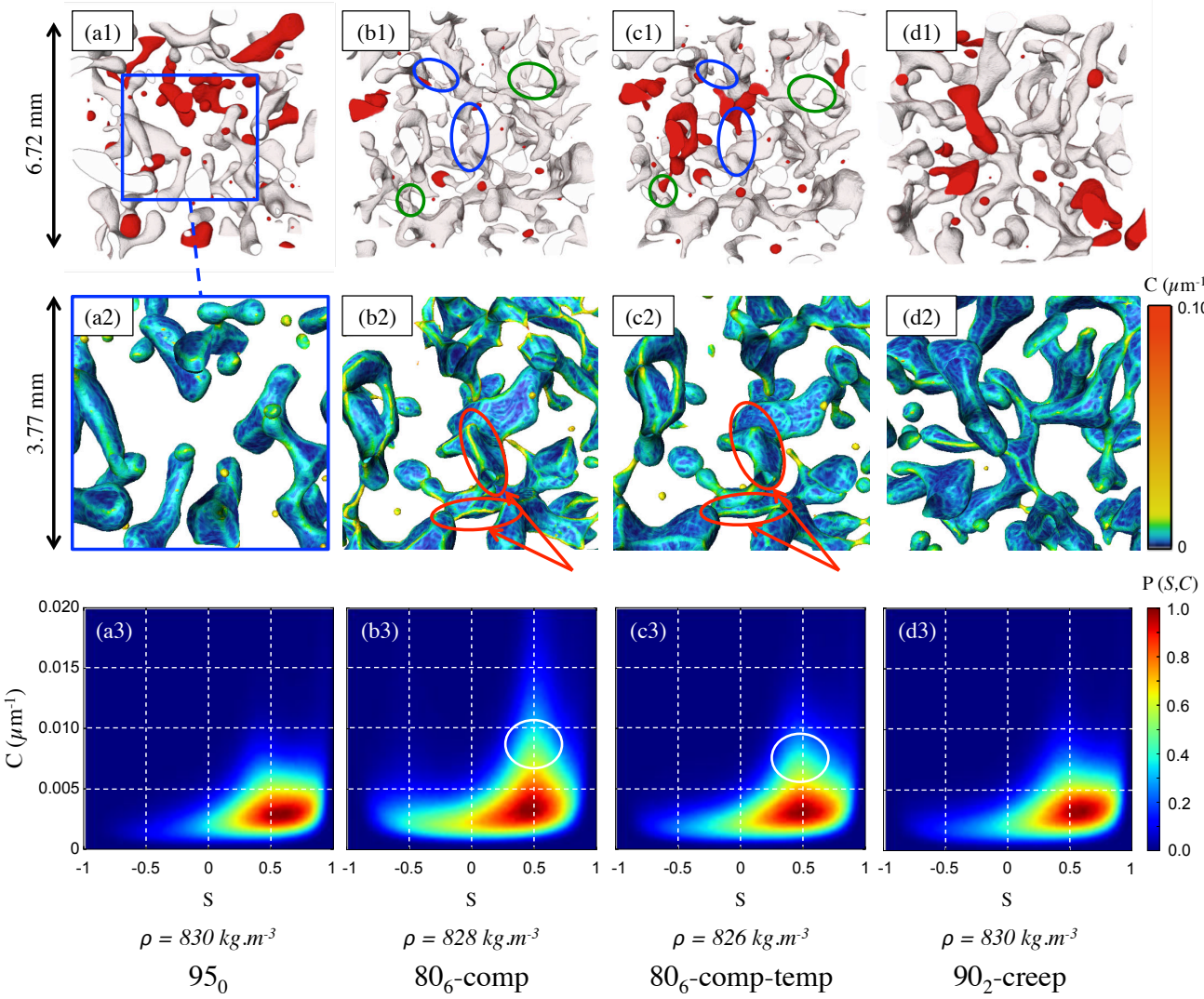

$\rho=828 \mathrm{~kg} \cdot \mathrm{m}^{-3}$

$\rho=826 \mathrm{~kg} \cdot \mathrm{m}^{-3}$

$\rho=830 \mathrm{~kg} \cdot \mathrm{m}^{-3}$

$80_{6}$-comp-temp

$90_{2}$-creep

Figure 6: Comparison of pore morphologies (rows 1-2) and local curvatures (rows 2-3) for samples of approximately equal density $\left(\rho=828 \pm 2 \mathrm{~kg} \cdot \mathrm{m}^{-3}\right)$ but resulting from different process histories. (a) $95_{0}$, (b) $80_{6}$-comp, (c) $80_{6}$-comp-temp and (d) $90_{2}$-creep. Blue and green ellipses highlight pore closure processes. Red ellipses indicate the smoothing of pores after heat treatment. White ellipses emphasize isolines around $\mathrm{P}(S, C) \approx 0.5$. See Table 1 for sample nomenclature. 
months. Most of the local surfaces have shapes between the saddle-ridge and the dome, with low curvedness. In comparison to Fig. 4a2 and Fig. 4b2, the distributions of local shapes of those samples $\left(95_{0}, 80_{6}\right.$-comp, $80_{6}$-comptemp and $90_{2}$-creep) are slightly shifted towards the cap-like shape $(S=1)$ as samples come from a deeper slice (94.5 m instead of $79.92 \mathrm{~m}$ ) or are denser $\left(829 \mathrm{~kg} \cdot \mathrm{m}^{-3}\right.$ instead of $\left.785 \mathrm{~kg} \cdot \mathrm{m}^{-3}\right)$.

In contrast to Fig. 4a2-b2, Fig. 6 b3 displays a larger distribution of local pore shapes after compaction. In addition, this curvature map (80 $86_{6}$-comp, Fig. 6b3) looks very similar to all other in situ compacted samples ( $80_{3}$-comp, $80_{4}$-comp and $80_{5}$-comp). Negative values are much more prevalent than for Figs. $6 \mathrm{a} 3\left(95_{0}\right)$ and $6 \mathrm{~d} 3$ (90 of concavities. This is due to the flattening of pores during the compaction. Similarly to Fig. 6c3 (80-comp-temp), the dominant local shape of Fig. 6b3 $\left(80_{6}\right.$-comp) is the cylinder as $S_{\max }$ is centered around $S=0.5$. The distribution is more widespread for $80_{6}$-comp than for $80_{6}$-comp-temp, but the most striking difference comes from the curvedness. The maximum curvedness value of the isoline $\mathrm{P}(S, C)=0.5$ is roughly $14 \%$ larger after compaction than after heat treatment, as pointed out by white ellipses on Fig. 6. This is a quantitative assessment of the evolution of the acute shapes observed in Fig. $6 \mathrm{~b} 2\left(80_{6}\right.$-comp $)$ towards the smoother shapes of pores observed in Fig. 6c2 (80

\section{Grain size}

Compaction tests also impacts ice grains according to microstructural analyses. In fact, Fig. 7 focuses on four microstructures representing different firn states (ex situ reference state, in situ -comp, -comp-temp and -creep). 
Note that we have access to the grain size only at the end of the in situ experimental tests. The ex situ sample $95_{0}$ exhibits a larger mean grain size than the in situ compacted sample 805-comp (see Fig. 7a1 and 7b1). Overall, the mean grain size of an ex situ sample is always larger compared to the mean grain size of an in situ compacted sample with the same or larger density. This is simply because of the duration of the compaction experiment, which is too short to notice any grain growth. The mean grain size of sample $80_{3}$-comp is similar to its value before compaction (if compared to Fig. 4a3, $\left.\langle\bar{A}\rangle=0.82 \mathrm{~mm}^{2}\right)$, but the final strain was small $(\varepsilon=5.90 \%)$. It has a lower value around $0.40 \mathrm{~mm}^{2}$ for samples $80_{4}$-comp and $80_{5}$-comp (with standard deviations equal to the mean grain size for all samples). The decrease in mean grain size for samples $80_{4}$-comp and $80_{5}$-comp could be consistent with dynamic recrystallization which can be expected for the temperature and strain-rate conditions imposed here [43]. Dynamic recrystallization would also explain the many small grains observed in Fig. 7b1. Moreover, features of dynamic recrystallization have been shown even for ex situ samples [28], and more generally in some firn cores [44]. However, the size of the thin sections $(L=18 \mathrm{~mm}, l=8 \mathrm{~mm})$ for these in situ samples was small with less than a hundred grains, possibly affecting representativeness. In any case, grain growth is excluded in these eight-hour experiments. The study of the c axis orientations in the Dome $\mathrm{C}$ firn (ex situ samples) shows the initial development of fabric with the c axes becoming aligned with the vertical core axis (see full fabric analysis for ex situ samples in Burr [28]). In the case of the compaction test $80_{5}$-comp (Fig. 7b2), the fabric is a little more pronounced than the ex-situ sample $95_{0}$ (Fig. 7a2). This is coherent with a 

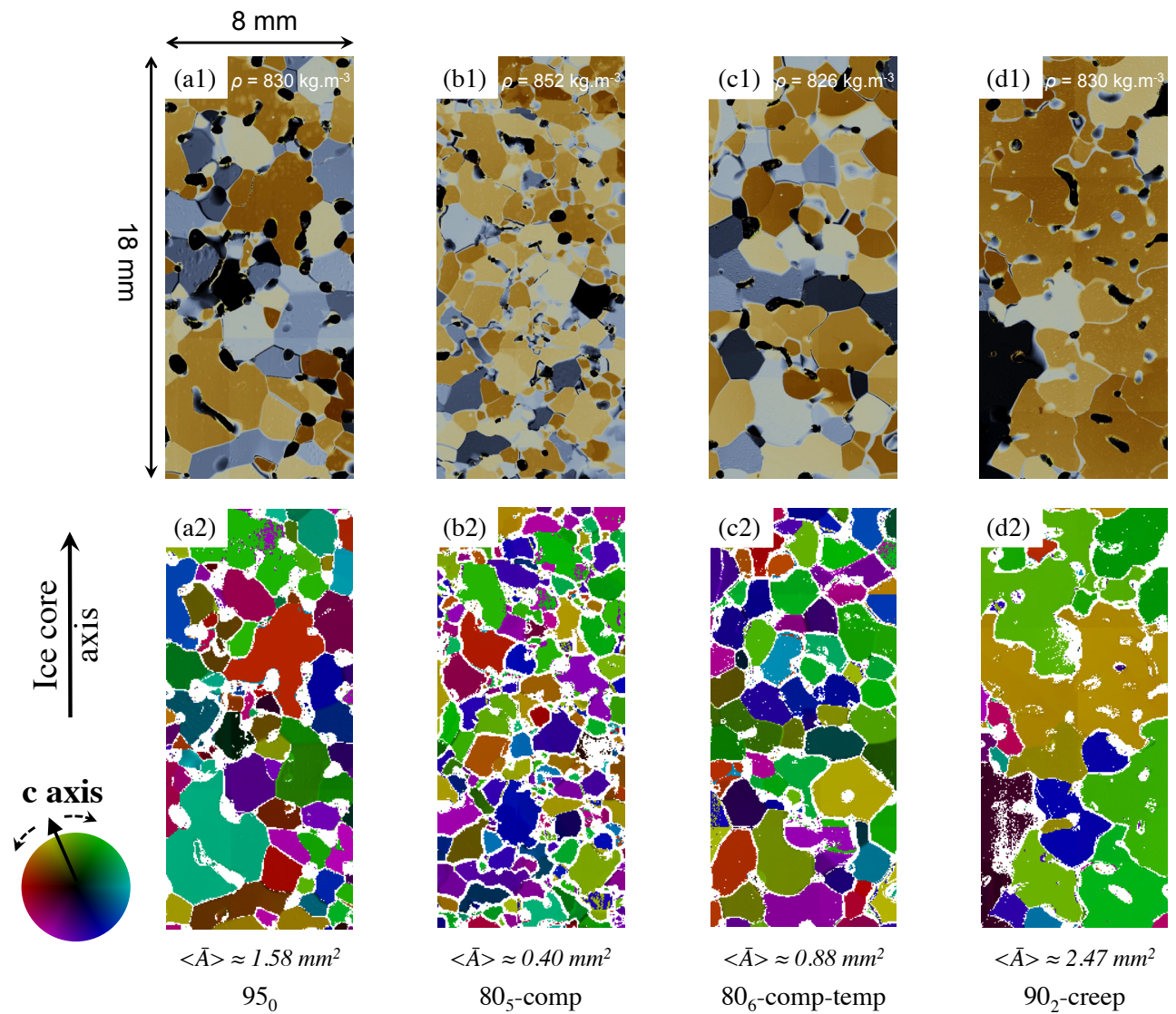

$<\bar{A}>\approx 0.88 \mathrm{~mm}^{2}$

$80_{6}$-comp-temp

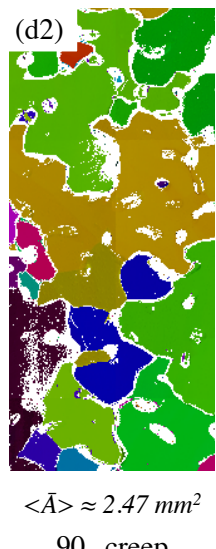

Figure 7: Comparison of the microstructures and $\mathbf{c}$ axis orientations of (a1)-(a2) 95, (b1)-(b2) 805-comp, (c1)-(c2) 806-comp-temp and (d1)-(d2) 902-creep.

preferential mechanism of dislocation creep during in situ compaction test.

However, asserting sample texture is not appropriate when only a few grains are observable as for the $90_{2}$-creep sample for instance (Fig. $7 \mathrm{~d} 1$ ). In any case, quantifying the rotation of $\mathbf{c}$ axes and the strength of the fabric is beyond the scope of this work.

Despite the rather high storage temperature at $-2^{\circ} \mathrm{C}$, no noticeable differences were observed when comparing samples $80_{1}$-temp and $90_{1}$-temp to 
their reference states Fig. 4a3 and Fig. 4b3 respectively. Thus, there are not shown. However samples $80_{2}$-creep and $90_{2}$-creep (Fig. $7 \mathrm{~d} 1$ ) that were crept at $-2{ }^{\circ} \mathrm{C}$ for five months, have a larger mean grain size than initially (compare Fig. 7d with Fig. 4b3), but also larger than those only heat treated (801-temp and $90_{1}$-temp) or than ex situ sample of the same density $95_{0}$ (compare Fig. $7 \mathrm{~d} 1$ and Fig. 7a1). As for sample 806-comp-temp (Fig. 7c1), features of recrystallization are hardly noticeable, and its grain size is similar to the one shown in Fig. 4a3. It is difficult to evaluate in which proportion dynamic recrystallization occurred.

\section{Discussion}

In situ characterization revealed large differences with ex situ results both for pore morphology and for pore closure. In particular, during in situ compaction tests, rate dependency was observed, with stresses about one order of magnitude larger than in firn cores (from which the samples are taken). The strain rates used in these tests are also large compared to polar firn densification rates (about 6 orders of magnitude larger). The durations involved during in situ tests are much too short for slow thermally activated processes to occur. The eight-hour in situ experiment represents about a thousand years of densification in Dome $\mathrm{C}$ for the same reached density. It is not possible to reproduce grain growth and sintering during this short time. The differences in closed porosity ratio and connectivity index observed between ex situ and in situ compacted samples come from this rate dependency. Thus, our tests decoupled the effect of viscoplastic deformations but thereby excludes also potential dynamic feedbacks between diffusion processes and 
dislocation glide. According to the sharpening of pore morphology, texture observations and strain rates, dislocation creep was the dominant mechanism during compaction. It has been previously shown that such mechanism occurs essentially by basal glide for ice and is strongly anisotropic (see Burr et al. [45], Chauve et al. [46] for recent updates on that subject).

To counteract these differences, some in situ samples were kept at $-2{ }^{\circ} \mathrm{C}$. Figures 5 and 6 prove that high temperature and time facilitate pore closure and pore rounding. But, closure also depends on the initial microstructure. Indeed, between samples $90_{1}$ and 901-temp, curvature variations are small. These are much less important than for samples $80_{6}$-comp and $80_{6^{-}}$ comp-temp for instance. Therefore, surface minimization (defined by the difference between the mean curvature and the local curvature), which is one of the driving forces for pore closure is different for these samples. Despite this difference, closure occurs for both $90_{1}$-temp and $80_{6}$-comp-temp samples (Fig. 5). We have shown that closure was heterogeneous between approximately $87 \mathrm{~m}$ and $98 \mathrm{~m}$ for ex situ firn due to the presence of small pore channels [7]. This means that closure is particularly accelerated in a certain range of depths, namely for a particular type of microstructure. More samples should be tested to reach a firmer conclusion on this topic.

Sample $80_{6}$-comp-temp (Fig. $7 \mathrm{c} 1$ ), which was compacted and then heat treated, exhibits a grain morphology surprisingly close to $80_{1}$-temp (only heat treated), thus close to its reference state Fig. 4a3. However, in agreement with the anisotropic plasticity, the $\mathbf{c}$ axes of $80_{6}$-comp-temp are still more aligned with the loading direction (Fig. 7c2). For all compacted samples $\left(80_{3}\right.$-comp, $80_{4}$-comp, $80_{5}$-comp and $80_{6}$-comp-temp), no clear sign of 
recrystallization is noticed.

Indeed, in situ compaction experiments are rather fast $\left(>10^{-6} \mathrm{~s}^{-1}\right)$ with large stresses (from $1 \mathrm{MPa}$ to $5 \mathrm{MPa}$, see SI) while the creep experiment is closer to what Chauve et al. [47] carried out, with stresses smaller than $1 \mathrm{MPa}$. However, crystal nucleation along grain boundaries such as necklaces of grains is not observed for any of our experiments contrary to what these authors observed in columnar ice [47]. Capolo [48] also observed drastic recrystallization after a few hours of creep under $\approx 0.3 \mathrm{MPa}$ stress on ice tricrystal. Serrated grain boundaries (evidence of grain boundary migration) are also not noticed in contrast to observations from Montagnat et al. [49] or Capolo [48]. However resolution of our images may hinder close inspection. Examination of thin sections reveals that there are less small grains for sample $80_{6}$-comp-temp than for ex situ and in situ compacted samples. This could mean an effective annealing of the sample excluding nucleation or rotation recrystallization. Nevertheless, we would have expected grains to grow in that case and we do not see a particularly marked increase in grain size. Again, the small number of observable grains calls for caution.

Samples $80_{2}$-creep and $90_{2}$-creep reached vertical strains of $\approx 6.6 \%$ and $11.9 \%$, respectively. Therefore secondary creep should be reached, and dynamic recrystallization should take place $[49,50]$. In addition, as the grain size is larger than initially, it is likely that high temperature also activated diffusion mechanism during creep. Meanwhile, according to the very few grains observed, the $\mathbf{c}$ axes of these samples do show a quite strong girdle textures (stronger for $90_{2}$-creep shown in Fig. $7 \mathrm{~d} 2$ than for $80_{2}$-creep). This, combined with the microstructure of Fig. $7 \mathrm{~d} 1$ reminds of grain boundary mi- 
gration mechanism, which happens in the deepest part of ice cores when large grains interlock as dynamic recrystallization proceeds [51, 52, chap. 6]. Highresolution images and precise measurements of the orientation with the help of EBSD should enhance our comprehension of the underlying mechanisms $[49,47]$.

\section{Conclusion}

In this paper, we presented three different experiments in order to discern the mechanisms of densification of polar firn. In situ oedometric compaction tests of Dome $\mathrm{C}$ firn were carried out under X-ray at $-10^{\circ} \mathrm{C}$ during a few hours. It was possible to characterize the evolution of pore curvature during densification and to follow the closure of pores. The connectivity index appears to be a good indicator of pore closure phenomena as it is not dependent of cut pores at the sample boundary as is the closed porosity ratio [7]. Since, by construction, lab experiments will never be able to reproduce the evolution on climatological time scales, it is important to exploit the ratetemperature equivalence as much as possible for aiming at it. Therefore, the second experiment consisted in studying the effect of temperature on firn through heat treatment (ageing at $-2{ }^{\circ} \mathrm{C}$ ) during a few months. The third one involved creep tests, i.e. compaction of firn performed at high temperature $\left(-2^{\circ} \mathrm{C}\right)$ during 5 months to combine the two previous experiments.

It is reported here that in situ compaction at high strain rates (between $2 \cdot 10^{-6} \mathrm{~s}^{-1}<\dot{\varepsilon}_{z}<1.5 \cdot 10^{-5} \mathrm{~s}^{-1}$, larger than natural strain rates in Antartica) results in densification with a reduced volume of closed pores compared to the natural conditions of the ice cap for the same firn density. In addition, 
the connectivity index decreases, but at higher densities than for the ex situ profile. On the contrary, heat treatments lead to pore closure without significantly changing the density. Creep tests allow to combine at the same time the densification and the closure of pores.

These experiments highlight that densification of firn in ice cap activates both physical mechanisms: it is an interplay between dislocation glides and diffusion processes. The dislocation glides lead to intragranular deformation with $\mathbf{c}$ axis orientation evolution (the ice viscoplastic behavior is strongly anisotropic) and to an increase in density.

The second mechanism leads to atomic diffusion, especially on the surface, which makes it possible, for example, to smooth pores by minimizing curvature and increasing the size of the grains. This last mechanism closes also some pores but it does not seem to change density in the range investigated in our experiments. Therefore, microstructure evolution of polar firn should depend on the history of each of the parameters influencing the local flow of ice cap. In return, the microstructure and not only the density should ultimately influence the capture of gases. In conclusion, we believe that the anisotropy of ice viscoplasticity should be considered in polar firn densification models as it would better represent ice crystal deformation than the common use of the isotropic power law of ice [e.g., 53], and may ultimately give different past climate reconstructions. It is also noteworthy that pore closure could be modeled by curvature minimization given appropriate diffusion coefficient. The physical model proposed by Flin et al. [24, 54] for snow metamorphism could be adapted for firn. This would help understand coalescence or separation of pores. It would also offer an alternative approach to 
the classical use of empirical parameterizations of the closed-porosity ratio when modeling gas transport in firn [55].

\section{Acknowledgements}

The authors would like to thank Pierre Latil (Novitom) for lending the compaction device. Mathieu Bourcier and Clément Ballot are also thanked for their help during X-ray scans. Labex OSUG@2020 and CEMAM are thanked for financial support for the micro-computed tomograph located at CMTC-UGA (Univ. Grenoble Alpes). Field personnels at Dome Concordia are also thanked (Joel Savarino, Philippe Possenti and wintering of the Concordia station). Agence Nationale de la Recherche (ANR) via contract NT09-431976-VOLSOL is acknowledged for the financial support for acquiring the ice core sections at Dome Concordia.

\section{References}

[1] M. Battle, M. L. Bender, T. Sowers, P. P. Tans, J. Butler, J. Elkins, J. Ellis, T. J. Conway, N. Zhang, P. Lang, A. Clarke, Atmospheric gas concentrations over the past century measured in air from firn at the South Pole, Nature 383 (1996).

[2] T. Sowers, M. Bender, D. Raynaud, Y. Korotkevich, $\delta 15 \mathrm{n}$ of n2 in air trapped in polar ice: A tracer of gas transport in the firn and a possible constraint on ice age-gas age differences, Journal of Geophysical Research: Atmospheres 97 (1992) 15683-15697. 
[3] N. Maeno, T. Ebinuma, Pressure Sintering of Ice and Its Implication to the Densification of Snow at Polar Glaciers and Ice Sheets, Journal Physical Chemistry 169 (1983) 4103-4110. doi:10.1021/j100244a023.

[4] S. A. Gregory, M. R. Albert, I. Baker, Impact of physical properties and accumulation rate on pore close-off in layered firn, Cryosphere 8 (2014) 91-105. doi:10.5194/tc-8-91-2014.

[5] R. Lomonaco, M. Albert, I. Baker, Microstructural evolution of finegrained layers through the firn column at Summit, Greenland, Journal of Glaciology 57 (2011) 755-762. doi:10.3189/002214311797409730.

[6] C. F. Schaller, J. Freitag, O. Eisen, Gas enclosure in polar firn follows universal law, Climate of the Past Discussions 1 (2017) 1-12.

[7] A. Burr, C. Ballot, P. Lhuissier, P. Martinerie, C. L. Martin, A. Philip, Pore morphology of polar firn around closure revealed by x-ray tomography, The Cryosphere 12 (2018) 2481-2500. doi:10.5194/ tc-12-2481-2018.

[8] J. K. Landauer, The Creep of Snow under Combined Stress, Journal of Rheology 2 (1958) 175. doi:10.1122/1.548829.

[9] T. Ebinuma, N. Maeno, Experimental studies on densification and pressure-sintering of ice, Annals Of Glaciology 6 (1985) 83-86. doi:10. 3189/1985AoG6-1-83-86.

[10] T. Ebinuma, N. Maeno, Particle Rearrangement and dislocation creep in a snow-densification process, Le Journal de Physique Colloques 48 (1987) C1-263-C1-269. doi:10.1051/jphyscol : 1987137. 
[11] B. Meussen, O. Mahrenholtz, H. Oerter, Creep of polar firn, Cold Regions Science and Technology 29 (1999) 177-200.

[12] S. Rolland Du Roscoat, A. King, A. Philip, P. Reischig, W. Ludwig, F. Flin, J. Meyssonnier, Analysis of Snow Microstructure by Means of XRay Diffraction Contrast Tomography, Advanced Engineering Materials 13 (2011) 128-135. doi:10.1002/adem. 201000221.

[13] X. Wang, I. Baker, Observation of the microstructural evolution of snow under uniaxial compression using X-ray computed microtomography, Journal of Geophysical Research: Atmospheres 118 (2013) 12,37112,382. doi:10.1002/2013JD020352.

[14] S. Schleef, H. Löwe, X-ray microtomography analysis of isothermal densification of new snow under external mechanical stress, Journal of Glaciology 59 (2013) 233-243. doi:10.3189/2013JoG12J076.

[15] S. Schleef, H. Löwe, M. Schneebeli, Hot-pressure sintering of low-density snow analyzed by X-ray microtomography and in situ microcompression, Acta Materialia 71 (2014) 185-194. doi:10.1016/j.actamat.2014.03. 004.

[16] M. Schneebeli, S. A. Sokratov, Tomography of temperature gradient metamorphism of snow and associated changes in heat conductivity, Hydrological Processes 18 (2004) 3655-3665. doi:10.1002/hyp. 5800.

[17] P. P. Ebner, M. Schneebeli, A. Steinfeld, Tomography-based monitoring of isothermal snow metamorphism under advective conditions, The Cryosphere 9 (2015) 1363-1371. doi:10.5194/tc-9-1363-2015. 
[18] K. Hammonds, R. Lieb-lappen, Z. Courville, A. Song, X. Wang, I. Baker, Laboratory investigations on the thermophysical properties of the icesnow interface while under a controlled temperature gradient, in: Proceedings, International Snow Science Workshop, Banff, 2014, pp. 35-42.

[19] N. Calonne, F. Flin, C. Geindreau, B. Lesaffre, S. Rolland du Roscoat, Study of a temperature gradient metamorphism of snow from 3-D images : time evolution of microstructures, physical properties and their associated anisotropy, The Cryosphere 8 (2014) 2255-2274. doi:10.5194/tc-8-2255-2014.

[20] C. Chandel, P. K. Srivastava, P. Mahajan, Micromechanical analysis of deformation of snow using X-ray tomography, Cold Regions Science and Technology 101 (2014) 14-23. doi:10.1016/j.coldregions. 2014. 01.005 .

[21] A. Wautier, C. Geindreau, F. Flin, Linking snow microstructure to its macroscopic elastic stiffness tensor: A numerical homogenization method and its application to 3-D images from X-ray tomography, Geophysical Research Letters 42 (2015) 8031-8041. doi:10.1002/ 2015 GL065227.

[22] A. Wautier, C. Geindreau, F. Flin, Numerical homogenization of the viscoplastic behavior of snow based on X-ray tomography images, The Cryosphere 11 (2017) 1465-1485.

[23] F. Flin, J. B. Brzoska, B. Lesaffre, C. Coléou, R. A. Pieritz, Threedimensional geometric measurements of snow microstructural evolution 
under isothermal conditions, Annals of Glaciology 38 (2004) 39-44. doi:10.3189/172756404781814942.

[24] F. Flin, J. B. Brzoska, The temperature-gradient metamorphism of snow: Vapour diffusion model and application to tomographic images, Annals of Glaciology 49 (2008) 17-21. doi:10.3189/ 172756408787814834 .

[25] T. U. Kaempfer, M. Schneebeli, Observation of isothermal metamorphism of new snow and interpretation as a sintering process, Journal of Geophysical Research 112 (2007) D24101. doi:10.1029/2007 JD009047.

[26] M. Kerbrat, B. Pinzer, T. Huthwelker, H. W. Gäggeler, M. Ammann, M. Schneebeli, Measuring the specific surface area of snow with Xray tomography and gas adsorption: comparison and implications for surface smoothness, Atmospheric Chemistry and Physics Discussions 7 (2007) 10287-10322. doi:10.5194/acpd-7-10287-2007.

[27] D. Veres, L. Bazin, A. Landais, H. Toyé Mahamadou Kele, B. LemieuxDudon, F. Parrenin, P. Martinerie, E. Blayo, T. Blunier, E. Capron, et al., The Antarctic ice core chronology (AICC2012): An optimized multi-parameter and multi-site dating approach for the last 120 thousand years, Climate of the Past 9 (2013) 1733-1748. doi:10.5194/ cp-9-1733-2013.

[28] A. Burr, Investigation of pore closure during polar firn densification, Ph.D. thesis, Université Grenoble Alpes, 2017. URL: https://tel. archives-ouvertes.fr/tel-01725405. 
[29] J. Schindelin, I. Arganda-carreras, E. Frise, V. Kaynig, T. Pietzsch, S. Preibisch, C. Rueden, S. Saalfeld, B. Schmid, J.-y. Tinevez, D. J. White, V. Hartenstein, P. Tomancak, A. Cardona, Fiji - an Open Source platform for biological image analysis, Nature Methods 9 (2013). doi:10 . 1038/nmeth.2019.Fiji.

[30] V. Boulos, V. Fristot, D. Houzet, L. Salvo, P. Lhuissier, Investigating performance variations of an optimized GPU-ported granulometry algorithm To cite this version : Investigating performance variations of an optimized GPU-ported granulometry algorithm, in: Design and Architectures for Signal and Image Processing (DASIP), 2012 Conference on, Oct 2012, Karlsruhe, Germany, 2013, pp. 1-6. URL: https://hal .archives-ouvertes.fr/hal-00787861.

[31] M. Peternell, D. S. Russell-Head, C. J. L. Wilson, A technique for recording polycrystalline structure and orientation during in situ deformation cycles of rock analogues using an automated fabric analyser, Journal of Microscopy 242 (2011) 181-188. doi:10.1111/j.1365-2818. $2010.03456 . x$.

[32] F. Flin, J.-B. Brzoska, B. Lesaffre, C. Coléou, R. A. Pieritz, Full three-dimensional modelling of curvature-dependent snow metamorphism: first results and comparison with experimental tomographic data, Journal of Physics D: Applied Physics 36 (2003) A49-A54. doi:10.1088/0022-3727/36/10A/310.

[33] J. J. Koenderink, A. J. V. Doorn, Surface shape and curvature scales, Image Vision Comput. 10 (1992) 557-564. 
[34] J. Gibbs, K. A. Mohan, E. Gulsoy, A. Shahani, X. Xiao, C. Bouman, M. De Graef, P. Voorhees, The Three-Dimensional Morphology of Growing Dendrites, Scientific reports (2015) 1-9. doi:10.1038/srep11824.

[35] R. Daudin, S. Terzi, P. Lhuissier, J. Tamayo, M. Scheel, N. H. Babu, D. G. Eskin, L. Salvo, Particle-induced morphological modification of $\mathrm{Al}$ alloy equiaxed dendrites revealed by sub-second in situ microtomography, Acta Materialia 125 (2017) 303-310. doi:10.1016/j.actamat. 2016.12 .005 .

[36] Avizo, Avizo lite 9.2.0, https://www.fei.com/software/ avizo-for-materials-science/, 2017.

[37] T. Chauve, Aita toolbox, https://github.com/ThomasChauve/aita, 2017.

[38] J. Schwander, J.-M. Barnola, C. Andrié, M. Leuenberger, A. Ludin, D. Raynaud, B. Stauffer, The age of the air in the firn and the ice at Summit, Greenland, Journal of Geophysical Research 98 (1993) 28312838. doi:10.1029/92JD02383.

[39] C. M. Trudinger, I. G. Enting, D. M. Etheridge, R. Francey, V. A. Levchenko, L. P. Steele, Modeling air movement and bubble trapping in firn, Journal of Geophysical Research 102 (1997) 6747-6763.

[40] J. P. Severinghaus, M. O. Battle, Fractionation of gases in polar ice during bubble close-off: New constraints from firn air $\mathrm{Ne}, \mathrm{Kr}$ and $\mathrm{Xe}$ observations, Earth and Planetary Science Letters 244 (2006) 474-500. doi:10.1016/j.epsl.2006.01.032. 
[41] L. E. Mitchell, C. Buizert, E. J. Brook, D. J. Breton, J. Fegyveresi, D. Baggenstos, A. Orsi, J. Severinghaus, R. B. Alley, M. Albert, R. H. Rhodes, J. R. McConnell, M. Sigl, O. Maselli, S. Gregory, J. Ahn, Observing and modeling the influence of layering on bubble trapping in polar firn, Journal of Geophysical Research Atmospheres 120 (2015) 2558-2574. doi:10.1002/2014JD022766.

[42] P. Martinerie, D. Raynaud, D. M. Etheridge, J. M. Barnola, D. Mazaudier, Physical and climatic parameters which influence the air content in polar ice, Earth and Planetary Science Letters 112 (1992) 1-13. doi:10.1016/0012-821X(92)90002-D.

[43] P. Duval, M. F. Ashby, I. Andermant, Rate-Controlling Processes in the Creep of Polycrystalline Ice, Journal of Physical Chemistry 87 (1983) 4066-4074.

[44] S. Kipfstuhl, S. H. Faria, N. Azuma, J. Freitag, I. Hamann, P. Kaufmann, H. Miller, K. Weiler, F. Wilhelms, Evidence of dynamic recrystallization in polar firn, Journal of Geophysical Research: Solid Earth 114 (2009) 1-10. doi:10.1029/2008JB005583.

[45] A. Burr, W. Noël, P. Trecourt, M. Bourcier, F. Gillet-Chaulet, A. Philip, C. L. Martin, The anisotropic contact response of viscoplastic monocrystalline ice particles, Acta Materialia 132 (2017) 576-585. doi:10.1016/ j. actamat. 2017.04.069.

[46] T. Chauve, M. Montagnat, S. Piazolo, B. Journaux, J. Wheeler, F. Barou, D. Mainprice, A. Tommasi, Non-basal dislocations should 
be accounted for in simulating ice mass flow, Earth and Planetary Science Letters 473 (2017) 247-255. doi:10.1016/j.epsl.2017.06.020.

[47] T. Chauve, M. Montagnat, F. Barou, K. Hidas, A. Tommasi, D. Mainprice, Investigation of nucleation processes during dynamic recrystallization of ice using cryo-EBSD, Philosophical Transactions of the Royal Society A: Mathematical, Physical and Engineering Sciences 375 (2017) 20150345. doi:10.1098/rsta.2015.0345.

[48] L. Capolo, Contribution à l'étude des hétérogénéités de déformation viscoplastique de la glace Ih mono et multi cristalline : essais de compression in-situ sous rayonnement X, Ph.D. thesis, Université Joseph Fourier - Grenoble 1, 2007.

[49] M. Montagnat, T. Chauve, F. Barou, A. Tommasi, B. Beausir, C. Fressengeas, Analysis of Dynamic Recrystallization of Ice from EBSD Orientation Mapping, Frontiers in Earth Science 3 (2015) 1-13. doi:10. 3389/feart. 2015.00081.

[50] T. Chauve, M. Montagnat, P. Vacher, Strain field evolution during dynamic recrystallization nucleation; A case study on ice, Acta Materialia (2015). doi:10.1016/j.actamat.2015.08.033.

[51] P. Duval, O. Castelnau, Dynamic Recrystallization of Ice in Polar Ice Sheets, Journal de Physique IV 5 (1995) 197-203.

[52] E. M. Schulson, P. Duval, et al., Creep and fracture of ice, volume 1, Cambridge University Press Cambridge, 2009. 
[53] C. Bréant, P. Martinerie, A. Orsi, L. Arnaud, A. Landais, Modelling the firn thickness evolution during the last deglaciation: constrains on sensitivity to temperature and impurities, Climate of the Past 13 (2017) 833-853. doi:https://doi .org/10.5194/cp-13-833-2017.

[54] F. Flin, N. Calonne, R. Denis, R. Caneill, B. Lesaffre, A. Dufour, A. Philip, J. Roulle, S. R. Roscoat, C. Geindreau, 3D Growth Rates from Tomographic Images : Local Measurements for a Better Understanding of Snow Metamorphism - Application to Isothermal Metamorphism and Comparison with a Phase-Field Model, in: American Geophysical Union (AGU) Fall Meeting, American Geophysical Union (AGU) Fall Meeting, San Fransisco, USA, 14-18 December, 2015, 2015. doi:10.1002/2015GL063541.Flin.

[55] C. Buizert, P. Martinerie, V. V. Petrenko, J. P. Severinghaus, C. M. Trudinger, E. Witrant, J. L. Rosen, A. J. Orsi, M. Rubino, D. M. Etheridge, L. P. Steele, C. Hogan, J. C. Laube, W. T. Sturges, V. A. Levchenko, A. M. Smith, I. Levin, T. J. Conway, E. J. Dlugokencky, P. M. Lang, K. Kawamura, T. M. Jenk, J. W. C. White, T. Sowers, J. Schwander, T. Blunier, Gas transport in firn: Multipletracer characterisation and model intercomparison for NEEM, Northern Greenland, Atmospheric Chemistry and Physics 12 (2012) 4259-4277. doi:10.5194/acp-12-4259-2012. 


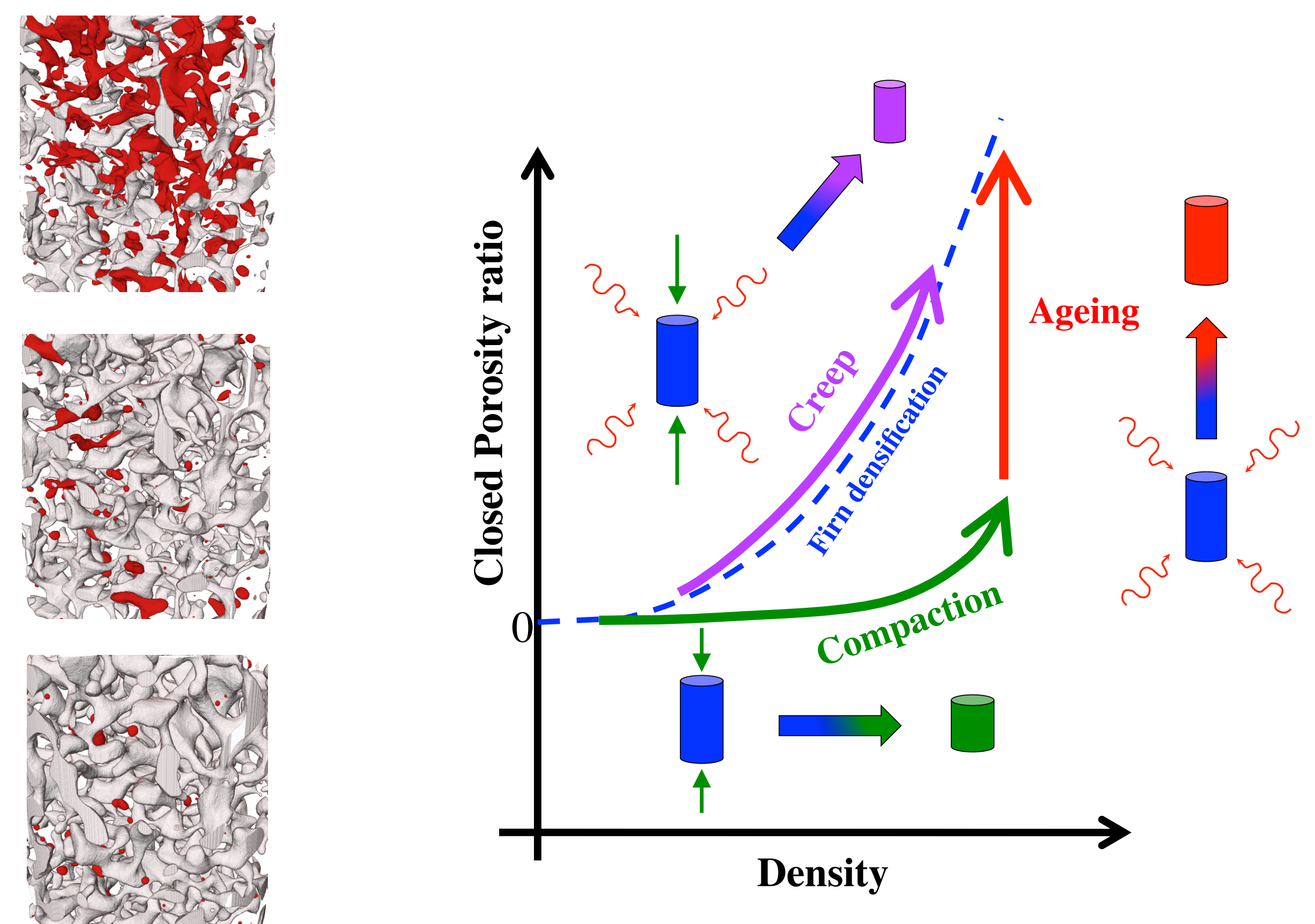

